\title{
AMCoR
}

Asahikawa Medical University Repository http://amcor.asahikawa-med.ac.jp/

Rheumatology international（2010.11）30巻12号:1635 1637.

Atypical Takayasu arteritis with solitary stenosis in the short segment of right axillary artery

Ikuta K, Torimoto Y, Shindo M, Sato K, Kohgo Y 


\section{Atypical Takayasu arteritis with solitary stenosis in the short segment of right axillary artery}

${ }^{1}$ Katsuya Ikuta, ${ }^{2}$ Yoshihiro Torimoto, ${ }^{1}$ Motohiro Shindo, ${ }^{1}$ Kazuya Sato, ${ }^{1}$ Yutaka Kohgo

${ }^{1}$ Division of Gastroenterology and Hematology/Oncology, Department of Medicine, Asahikawa Medical College

${ }^{2}$ Oncology Center, Asahikawa Medical College Hospital

2-1-1-1 Midorigaoka-Higashi, Asahikawa, Hokkaido 078-8510, Japan

\section{Corresponding author:}

Katsuya Ikuta, M.D., Ph.D.

Assistant Professor

Division of Gastroenterology and Hematology/Oncology

Department of Medicine

Asahikawa Medical College

2-1-1-1 Midorigaoka-Higashi, Asahikawa, Hokkaido 078-8510, Japan

Key words:

Takayasu arteritis; axillary artery; fever of unknown origin (FUO); Japanese; stenosis; short segment

\section{Disclosures:}

None 


\begin{abstract}
Takayasu arteritis is a rare, idiopathic, and chronic inflammatory large vessel vasculitis,
\end{abstract}

involving mainly the aorta and its major branches. Takayasu arteritis predominantly affects women. The clinical presentation is characterized by an acute phase with constitutional symptoms, followed by a chronic phase in which symptoms relate to stenosis or occlusion of vessels. We here report a rare case of Japanese male patient with a fever of unknown origin, and showed a solitary stenosis in the short segment of right axillary artery.

\title{
Introduction
}

Takayasu arteritis, also known as occlusive thromboaortopathy or pulseless disease, is a rare, idiopathic, and chronic inflammatory arteritis $[1,2]$. The common involved sites are the aorta and its major branches, and the pulmonary artery is also often affected [3]. Takayasu's arteritis predominantly affects women. The clinical presentation is characterized by an acute phase with constitutional symptoms such as fever and malaise, followed by a chronic phase in which symptoms relate to stenosis or occlusion of vessels [1-4]. We here report a rare case of Japanese male patient who presented as a fever of unknown origin, and showed a solitary stenosis in the short segment of right axillary artery.

\section{Case Report}


A 26-year-old Japanese male consulted a physician because of $38^{\circ} \mathrm{C}$ of fever that had persisted for 10 days and weight loss. At first he took non-steroidal anti-inflammatory drugs, but those were not effective at all. The physician tried to identify the cause of his fever, but specific origin was not identified. He was then referred to our department. He had suffered from cervical and lumber disc herniation when he was 16 years old, and he had fractured his nasal bone when he was 24 years old, but he did not feel any symptom related to those. He did not have any remarkable family history.

On admission, his body temperature was $37.1^{\circ} \mathrm{C}$. The blood pressure measured at right upper arm were 110/88 mmHg, while that was 136/68 mmHg measured at the left upper arm. He felt a slight tenderness in the back of his right upper arm. He also felt a muscle fatigue in that area. Pulsing in right radial artery was attenuated when he use right upper extremity, but vascular murmur was not heard at all.

Laboratory data on admission showed that WBC was $6.8 \times 10^{9} / \mathrm{L}$, and a platelet count of $380 \times 10^{9} / \mathrm{L}$. Hemoglobin concentration was $117 \mathrm{~g} / \mathrm{L}$, with MCV $86.1 \mathrm{fl}$ and MCHC 25.9\%, indicating normocytic anemia. Biochemical data showed no remarkable abnormality, except for C reactive protein (CRP) $100.3 \mu \mathrm{g} / \mathrm{ml}$ and erythrocyte sedimentation rate (ESR) $97 \mathrm{~mm} \mathrm{Hg} / \mathrm{hr}$. Among pro-inflammatory cytokines, IL-6 was elevated to $19.3 \mathrm{pg} / \mathrm{ml}$ (normal range: $<4.0 \mathrm{pg} / \mathrm{ml}$ ). Tumor markers, and the auto-reactive antibodies for collagen disease, including antinuclear antibody (ANA), anti-double stranded DNA-antibody, anti-single stranded DNA-antibody, anti-ribonucleoprotein (RNP)-antibody, and anti-Sm-antibody, were all negative. Cytoplasmic anti-neutorophil antibody 
(C-ANCA) and perinuclear anti-neutorophil cytoplasmic antibody (P-ANCA) were also both negative.

The tuberculin reaction was highly positive, but both the cultivation and polymerase chain reaction

(PCR) for tubercle bacillus of the sputum and gastric juice were negative.

Although blood examination could not reveal the cause of his fever, examination of urine showed bloody urine and serum anti-streptolysin O (ASO) and anti-streptokinase (ASK) were high to be $567.8 \mathrm{IU} / \mathrm{ml}$ and $680 \mathrm{x}$, respectively. Therefore, we first suspected the hemolytic streptococcal infection, and began intravenous piperacillin administration. At first CRP showed a mild decline, but then showed an increase again without normalization. We then focused on the findings of slight tenderness in his right upper arm and the difference of blood pressure between right arm and left arm. We decided to determine the possibility of Takayasu's arteritis, and magnetic resonance angiography (MRA) was performed.

MRA showed no stenosis or occlusion of aorta and its main branches. Therefore, angiography for the vessels of right upper arm was then performed.

Figure 1 showed the findings of angiography of the right upper arm. The extensive stenosis in the right axillary artery was found. Stenosis was only found in right axillary artery, and the stenosis was highly limited in short segment of right axillary artery. The infusion of a contrast material was performed until the collateral branches were well appeared. There was no stenosis or occulusion in the aorta trunk and its main branches, the vessels in left right upper arm, abdominal aorta and bilateral renal arteries. There was no stenosis or occlusion in the vessels of distal portion of his right upper 
arm.

He was given a diagnosis of Takayasu arteritis from the criterion by the American college

of rheumatology (ACR) (1990) [5]. Although there was no vascular bruit in his physical examination, his presentations met the other 4 criteria such as age, claudication of extremities, pulselessness, the difference between arms, abnormatilies found by angiography.

After diagnosis of Takayasu arteritis, $40 \mathrm{mg} /$ day of predonisolone (PSL) was started by intravenous administration, and then CRP was dramatically decreased, and his fever was also clearly disappeared. WBC was consistent throughout the treatment of PSL, so that it could not be considered as a marker of inflammation. Administration of PSL was gradually decreased. He did not feel any fever again, and PSL was finally stopped.

\section{Discussion}

We here reported a case of Takayasu arteritis presented as a fever of unknown origin (FUO) and only showed a short segment stenosis of right axillary artery. Takayasu arteritis is a nonspecidic chronic inflammatory disease, and its etiology has not been fully elucidated [1, 2]. Although the systemic symptoms such as fever might be often observed in Takayasu arteritis [4], most cases present other symptoms from stenosis or occlusion of vessels. Only few cases have been reported to present FUO as their first manifestations [6-11]. In present case, patient was male, and he had not felt any symptom except the fever. A careful physical examination fortunately enable us to find the faint 
findings of right upper arm and leaded to the final diagnosis in this case as Takayasu arteritis, which usually affects the aorta and its main branches; however, this case did not show any remarkable findings in those large vessels determined by MRA. Although angiography might be invasive procedure, we decided to perform it because any other modality could not clarify the cause of his symptoms. Fortunately, angiography revealed the stenosis, but the stenosis was highly limited in the short segment of right axillary artery. There have been some other reports that showed the stenosis or occlusion in axillary artery in Takayasu arteritis, but those cases also showed other lesions involved other vascular, such as subclavian arteries, vertebral arteries, and aorta [4, 12-14]. Our case showed only short segment stenosis in right axillary artery, and no other case with only such short segment lesion in axillary artery has been reported. Because we could not diagnose him as Takayasu arteritis without angiography, we would like to emphasize that angiography should still be the powerful tool for diagnosis of Takayasu arteritis.

Our case was diagnosed as Takayasu arteritis from ACR criteria, which was reported to demonstrate a high sensitivity of $90.5 \%$ and also a high specificity of $97.8 \%$ for the diagnosis of Takayasu arteritis [5]. There are some other disease entities that show vascular stenosis, such as Wegener granulomatosis, polyarteritis nodosa, giant-cell arteritis, and hypersensitivity vasculitis, and there are some reports with involvements of the axillary artery especially in the cases of giant-cell arteritis [15-17]. However, the clinical presentations of the present case did not meet the criteria for all of those. Therefore we finally diagnosed him as Takayasu arteritis and the treatment with PSL was 
started. His symptoms disappeared dramatically and then he have been well without taking any medications, however, there are no other case which resemble the present case so that the prognosis of this case might not be predicted and careful follow-up should be needed. 


\section{References}

1. Johnston SL, Lock RJ, Gompels MM (2002) Takayasu arteritis: a review. J Clin Pathol

55: $481-486$

2. Sheikhzadeh A, Tettenborn I, Noohi F, Eftekharzadeh M, Schnabel A (2002) Occlusive

thromboaortopathy (Takayasu disease): clinical and angiographic features and a brief review of

literature. Angiology 53: 29-40

3. Yamato M, Lecky JW, Hiramatsu K, Kohda E (1986) Takayasu arteritis: radiographic and

angiographic findings in 59 patients. Radiology 161: 329-334

4. Hall S, Barr W, Lie JT, Stanson AW, Kazmier FJ, Hunder GG (1985) Takayasu arteritis. A

study of 32 North American patients. Medicine (Baltimore) 64: 89-99

5. Arend WP, Michel BA, Bloch DA, Hunder GG, Calabrese LH, Edworthy SM, Fauci AS,

Leavitt RY, Lie JT, Lightfoot RW Jr, et al (1990) The American College of Rheumatology 1990

criteria for the classification of Takayasu arteritis. Arthritis Rheum 33: 1129-1134

6. Erten N, Saka B, Karan MA, Tascoglu C (2004) Takayasu arteritis presenting with Fever

of unknown origin: two case reports. J Clin Rheumatol 10: 16-20

7. Uthman IW, Bizri AR, Hajj Ali RA, Nasr FW, Khalil IM (1999) Takayasu's arteritis

presenting as fever of unknown origin: report of two cases and literature review. Semin Arthritis

Rheum 28: 280-285 
8. Sakakibara Y, Hiramatsu Y, Abe M, Ishimitsu T (1998) Unexplained fever and aortic

regurgitation: a rare presentation of Takayasu's aortitis--a case report. Angiology 49: 665-667

9. $\quad$ Tsai MJ, Lin SC, Wang JK, Chou CC, Chiang BL (1998) A patient with familial

Takayasu's arteritis presenting with fever of unknown origin. J Formos Med Assoc 97: 351-353

10. Yotsuyanagi H, Chikatsu N, Kaneko Y, Kurokawa K (1995) Takayasu's arteritis in

prepulseless stage manifesting lymph node swelling and hepatosplenomegaly. Intern Med 34:

455-459

11. Wu YJ, Martin B, Ong K, Klein NC, Cunha BA (1989) Takayasu's arteritis as a cause of fever of unknown origin. Am J Med 87: 476-477

12. Al-Awami S, Katz DA, Kreifels MF, Bogard PJ, Hayes DF (1984) Takayasu's arteritis of the upper extremities. A case report and review of literature. Angiology 35: 383-388

13. Scully RE, Mark EJ, McNeely BU (1981) Case records of the Massachusetts general hospital. Weekly clinicopathological exercises. N Eng J Med 305: 1519-1524

14. Iannone LA, Rayl KL (1991) Takayasu's disease with axillary, right coronary artery, and right internal mammary stenosis treated with angioplasty. Cathet Cardiovasc Diagn 22: 42-44

15. Kelly J, Rudd AG (2001) Giant cell arteritis presenting with arm claudication. Age Ageing 30: 167-169

16. Akdal G, Thurtell MJ, Halmagyi GM (2008) Giant cell arteritis presenting with bilateral vertebral and axillary artery occlusions. Intern Med J 38: 741-742 
17. Papadopoulos CG, Voulgari PV, Zioga A, Miltiadous GA, Nicolopoulos P, Elisaf MS,

Drosos AA (2008) Significant improvement of axillary artery stenosis in a 67 year-old woman with giant cell arteritis. Clin Exp Rheumatol 26(3 Suppl 49): S151-152 


\section{Figure legend}

Figure 1. The angiographic image for right upper extrimity. The schema for the vessels is also shown. The stenosis was observed in only quite limited segment of the right axillary artery. No other branch of artery was affected. 

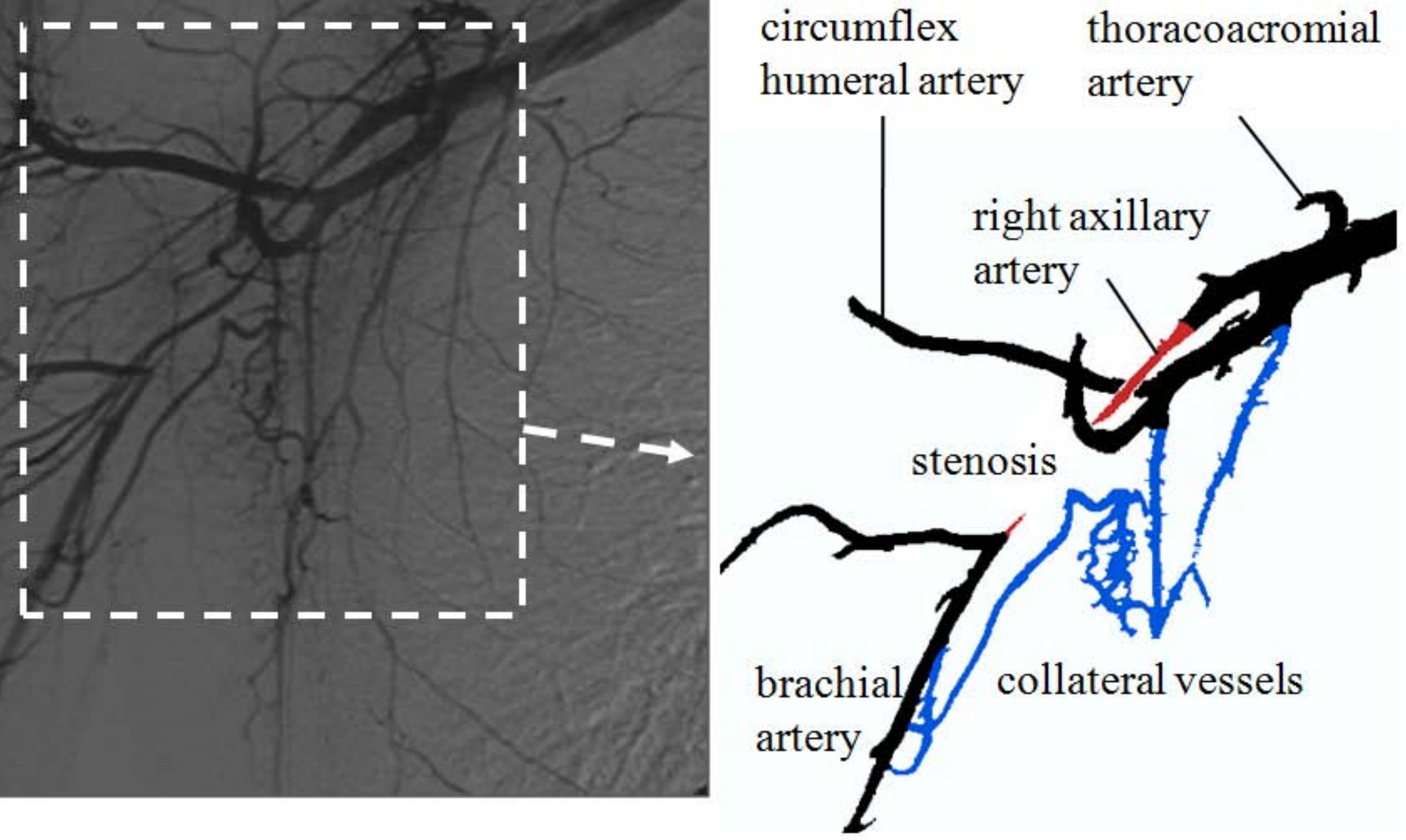